\title{
Stimulation of Aldosterone Biosynthesis in Adrenal Mitochondria by Sodium Depletion *
}

\author{
Elisa T. Marusic $\ddagger$ and Patrick J. Mulrow $\S$ \\ (From the Department of Internal Medicine, Yale University School of Medicine, \\ New Haven, Connecticut)
}

\begin{abstract}
The effect of various factors on the conversion of corticosterone to aldosterone was studied in an isolated mitochondrial system from rat adrenal glands. The adrenal mitochondrial fraction from rats on a low sodium diet has a greater capacity for converting corticosterone to aldosterone than mitochondria from rats fed a normal diet. After 1 day on a low sodium diet the amount converted was $162 \%$ and after the 2 nd and 4th day the amounts converted were 239 and $242 \%$, respectively, compared to a value of $100 \%$ for the control rats. Sodium and(or) potassium added in vitro did not affect the conversion of corticosterone to aldosterone.

The specificity of the sodium depletion stimulus on the conversion of corticosterone to aldosterone was established by comparing two other mitochondrial enzymes from glomerulosa cell mitochondria. Succinic dehydrogenase and $11 \beta$-hydroxylase were measured in normal and sodium-depleted rats and no difference in activity of either enzyme was found.

The data are consistent with the view that sodium depletion stimulates the last step in aldosterone biosynthesis by causing a specific enzymatic change in adrenal mitochondria.
\end{abstract}

\section{Introduction}

Sodium depletion is a potent stimulator of aldosterone secretion. This stimulation appears to be through a humoral mechanism. Although there are many studies on the regulation of aldosterone secretion, only a few attempt to define the site in the biosynthetic pathway that is stimulated by sodium depletion (1-5). One of the chief problems in such a study is that many of the steps in the aldosterone biosynthetic pathways are common to biosynthesis of other corticoids. Since these other corticoids and their precursors are pro-

* Received for publication 7 July 1967 and in revised form 14 August 1967.

Presented in part at the Annual Meeting of the American Society for Clinical Investigation, 1 May 1967.

Supported by U. S. Public Health Service Research Grant AM 05954-06.

$\$$ Postdoctoral Fellow USPHS, Grant I-FO 5 TW-883.

§ Research Career Development Award 5-K3-AM-4903.

Address requests for reprints to Dr. Patrick J. Mulrow,

Yale University School of Medicine, 333 Cedar Street,

New Haven, Conn. 06510. duced at a much greater rate than aldosterone, any changes in the aldosterone pathway may be masked when the whole adrenal gland is studied in vivo or in vitro.

The biosynthesis of aldosterone occurs in the zona glomerulosa of the adrenal gland and little, if any, takes place in the fasciculata-reticularis zones (6). The only step that is unique in the biosynthesis is the conversion of corticosterone to aldosterone, which occurs in the mitochondrial fraction (7-9). The steps involved are presumably corticosterone $\rightarrow 18$-hydroxycorticosterone $\rightarrow$ aldosterone. Only the production of aldosterone is specific for the zona glomerulosa. Some 18hydroxycorticosterone is synthesized in the zona fasciculata-reticularis as well, but the quantity appears to vary with different species $(3,7)$.

The present experiments were designed to determine whether in vivo sodium depletion stimulated the last steps in aldosterone biosynthesis: conversion of corticosterone to aldosterone. The rat was selected as the experimental animal since short- 
term sodium depletion can be easily induced and the zona glomerulosa can be readily separated from the inner zones (10). The use of the mitochondrial fraction eliminated the influence of corticosterone precursor pools on the conversion of corticosterone to aldosterone. The results indicate that short-term sodium depletion stimulates the last steps in aldosterone biosynthesis by producing a specific enzymatic change in adrenal glomerulosa cell mitochondria.

\section{Methods}

Male albino Sprague-Dawley rats, weighing 150-200 g were used in this study. The rats were fed a specially prepared diet with either a normal or low sodium content (11). The animals were killed by decapitation and the adrenal glands immediately removed, freed of fat, and homogenized in $0.25 \mathrm{M}$ sucrose. When only capsular tissue was used, it was obtained as described by Giroud et al. (10) and special care was taken to eliminate the inner zones. The capsules were then homogenized. The mitochondrial fraction was obtained by the method of Schneider (12). Protein nitrogen was determined by the Lowry method (13) and succinic dehydrogenase according to Slater and Bonner (14).

The incubation media, unless otherwise indicated, contained $40 \mathrm{~mm}$ potassium phosphate buffer $\mathrm{pH} 7.4,5 \mathrm{~mm}$ $\mathrm{MgCl}_{2}, 10 \mathrm{~mm}$ sodium fumarate, $0.25 \mathrm{~mm}$ NADP, $4.5 \mathrm{~mm}$ glucose-6-phosphate, and $1 \mathrm{U}$ of glucose-6-phosphate dehydrogenase in a final volume of $2 \mathrm{ml} .20 \mu \mathrm{g}$ of corticosterone- $-4-{ }^{14} \mathrm{C}$ was added to each flask which contained about $0.25 \mathrm{mg}$ of mitochondrial protein nitrogen. When the incubation was carried out in $20 \mathrm{~mm}$ Tris- $\mathrm{HCl}$ buffer $\mathrm{pH}$ 7.4, the same cofactors that were used in the phosphate buffer were added to the incubation media. In the KrebsRinger bicarbonate buffer only fumarate and the NADPH generating system were added in the concentrations indicated above. The incubation was carried out for $30 \mathrm{~min}$ at $37^{\circ} \mathrm{C}$ in air in a Dubnoff incubator; when a longer incubation time was used, the time is indicated in the results.

When $11 \beta$-hydroxylase activity was measured, $100 \mu \mathrm{g}$ of deoxycorticosterone (DOC) was added instead of corticosterone and the incubation was carried out for $15 \mathrm{~min}$. The amount of DOC converted to corticosterone was used as an index of $11 \beta$-hydroxylase activity.

Extraction and identification of the steroids. Tracer amounts of aldosterone-1,2- ${ }^{3} \mathrm{H}$ were added to correct for losses in purification. The samples were extracted with 10 volumes of methylene chloride. The extracts were washed sequentially with $1 / 10$ volume $0.05 \times \mathrm{NaOH}$, $0.1 \mathrm{M}$ acetic acid, and distilled water, and evaporated in vacuo. Stable aldosterone and cortisol were added and the dried residue was applied to a paper chromatogram and run in the formamide-chloroform system (15). The aldosterone and corticosterone areas were located by their absorption of ultraviolet light. The 18-hydroxycorticosterone area was located by radiochromatogram scanning and its $R_{s}$ (cortisol). Identification of this zone was accomplished in certain samples as previously described (7).

An aliquot of the aldosterone area from the first chromatogram was taken for counting and the remainder was rechromatographed in the Bush $B_{5}$ system, eluted, and acetylated with pyridine-acetic anhydride $1: 2$ for $24 \mathrm{hr}$. The acetylated derivative was chromatographed in the cyclohexane-benzene-methanol-water 100:50:100:25 and cyclohexane-dioxane-methanol-water $100: 100: 50: 25$ systems and the ${ }^{3} \mathrm{H} /{ }^{14} \mathrm{C}$ ratio was measured.

Aldosterone accounted for $89.2 \% \pm 3.7$ (mean and standard deviation of 11 experiments) of the radioactivity in the aldosterone area after the first chromatographic system. Since good purification was obtained from the first chromatogram system, these counts were used in most of the calculation. Each time conditions were changed, the diacetate was again made to check the aldosterone purity. In each instance there was no evidence of contamination.

The per cent of corticosterone- $4-{ }^{14} \mathrm{C}$ converted to 18 hydroxycorticosterone and aldosterone was calculated. Aldosterone- $-{ }^{14} \mathrm{C}$ counts were corrected for losses by ${ }^{3} \mathrm{H}$ tracer. No correction was made in the 18-hydroxycorticosterone samples. The aldosterone production in the samples incubated with stable DOC was measured by the double isotope technique (16). Corticosterone was measured by the acid fluorescence method (17). Radioactivity was measured with a Packard Tri-Carb liquid scintillation counter (Packard Instrument Co., Inc., Downers Grove, II1.). Corticosterone- $-4-{ }^{14} \mathrm{C}$ and $\mathrm{D}$-aldosterone- $1,2-{ }^{3} \mathrm{H}$ were obtained from New England Nuclear Corp. (Boston, Mass.) and purified by further paper chromatography.

\section{Results}

The conversion of corticosterone to aldosterone by the different adrenal cellular fractions is shown in Fig. 1. Whole homogenate, nuclear, mitochondrial, microsomal, and soluble fractions obtained from $100 \mathrm{mg}$ of adrenal tissue were incubated in the presence of $40 \mu \mathrm{g}$ of corticosterone-4-14 $\mathrm{C}$. Combinations of soluble fraction plus mitochondrial, and soluble fraction with microsomal fractions were also tested. As shown in Fig. 1, all the conversion activity is present in the mitochondrial fraction. The amount of aldosterone converted from corticosterone- $4-{ }^{14} \mathrm{C}$ from this fraction was $1.96 \%(0.78 \mu \mathrm{g}$ of aldosterone per $100 \mathrm{mg}$ of tissue). No further increase of activity of the mitochondrial fraction was observed when the soluble fraction was added to the incubation media (0.80 $\mu \mathrm{g}$ of aldosterone per $100 \mathrm{mg}$ of tissue). The small amount of conversion in the nuclear and microsomal fractions is probably due to mitochondrial contamination of these fractions.

The conversion of corticosterone to aldosterone 
PER CENT CONVERSION TO

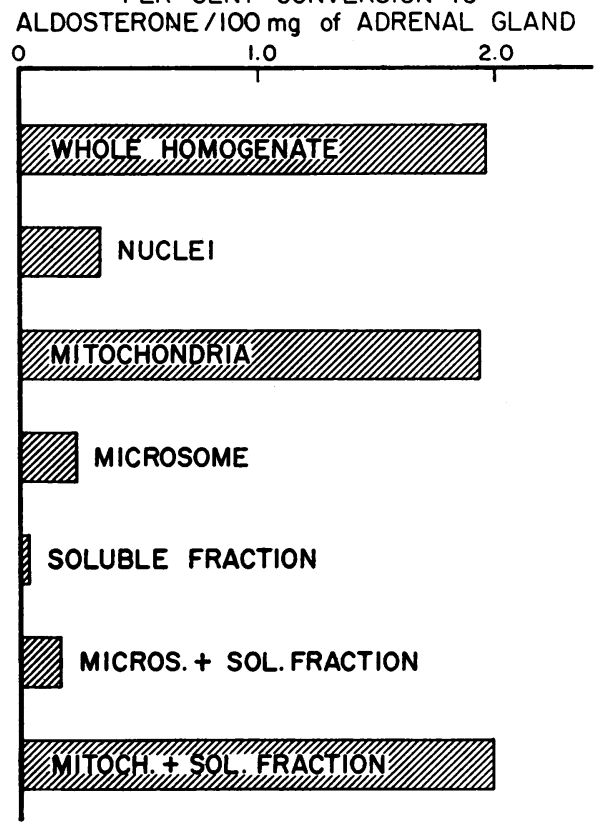

Fig. 1. CONVERsion OF CORTICOSTERONE-4- ${ }^{14} \mathrm{C}$ TO ALDOSTERONE BY DIFFERENT CELL FRACTIONS FROM THE WHOLE ADRENAL GLAND. Incubation conditions were as noted under Methods. $40 \mu \mathrm{g}$ of corticosterone $-4-{ }^{14} \mathrm{C}$ was used per flask. The incubation was carried out for $1 \mathrm{hr}$. Results are the mean of two experiments and are expressed as per cent corticosterone converted per $100 \mathrm{mg}$ adrenal gland.

by adrenal capsular mitochondria was compared with that of the inner zones in two experiments. The capsular mitochondria converted $11.6 \%$ of the corticosterone- $4-{ }^{14} \mathrm{C}$ added, while only $0.2 \%$ was converted by the fasciculata-reticularis mitochondria. This relationship was also observed in the sodium-depleted rats, where a conversion of $22.6 \%$ was found in the capsular mitochondria, and only $0.3 \%$ for the inner zones. These values are expressed as per cent of corticosterone converted to aldosterone per $0.25 \mathrm{mg}$ of mitochondrial nitrogen.

The effect of a low sodium diet on the conversion of corticosterone to aldosterone by adrenal mitochondria from the whole gland is shown in Fig. 2. The per cent converted per milligram of protein nitrogen by the mitochondrial fraction of rats maintained on a normal sodium diet (control rats) is expressed as $100 \%$ and the per cent converted by the sodium-depleted rats as per cent of controls. After 1 day on a low sodium diet there is an increase of $162 \%$ in the per cent of corticosterone converted to aldosterone, and this in- creases to 239 and $242 \%$ by the 2 nd and 4 th day of sodium depletion, respectively.

To determine if the supernatant fraction obtained from sodium-depleted rats might have had an effect on mitochondrial enzymatic activity, we performed two experiments in which the conversion of corticosterone to aldosterone was measured in the mitochondrial fraction from sodium-depleted rats with and without the addition of the supernatant fraction. The mitochondrial fraction alone had a conversion rate $264 \%$ greater than that of the control, while the mitochondrial fraction plus the supernatant fraction was also $260 \%$ greater, indicating that the supernatant fraction from sodium-depleted rats did not enhance the conversion of corticosterone to aldosterone. Moreover, the increased conversion by mitochondria from sodium-depleted rats is present regardless of whether furmarate, malate, or succinate was added as a source of substrate for the respiratory chain.

Furthermore, addition of NADPH to the incubation media was not necessary to show this difference between mitochondria from control or sodium-depleted rats. In three experiments in

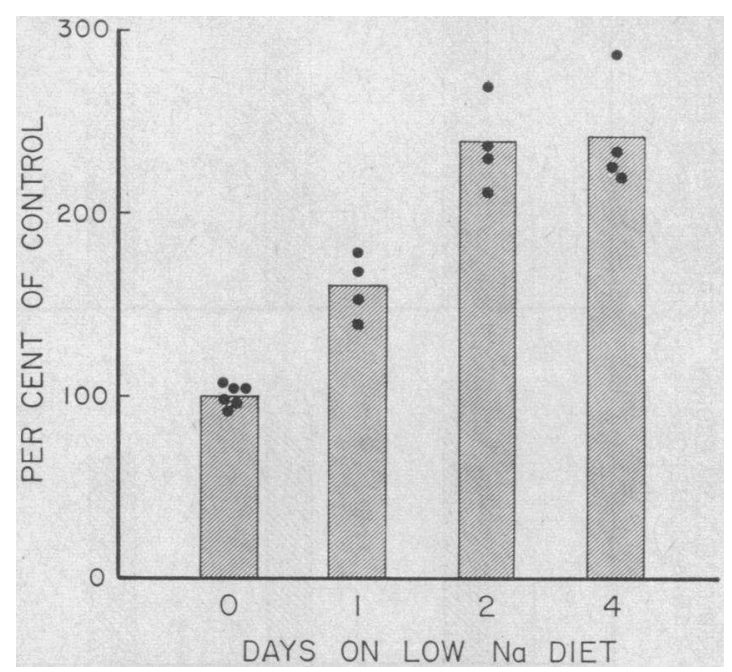

Fig. 2. Conversion of CORTICOSTERONe-4- ${ }^{14} \mathrm{C}$ TO ALDOSTERONE BY THE WHOLE ADRENAL MITOCHONDRIAL FRACTION OF RATS AFTER 0 (CONTROL), 1, 2, AND 4 DAYS OF A LOW SODIUM DIET. The results are expressed as per cent of the mean control value. The mean control value was $7.3 \%$ conversion per milligram of mitochondrial protein nitrogen; this value is expressed as $100 \%$. The range of conversion by the control mitochondria was between 6.4 and $7.9 \%$. Each dot represents the result of an individual experiment. 
which no NADPH was added to the media and malate was used instead of fumarate, 1 day of sodium depletion resulted in $173 \%$ greater conversion, and 2 days in $202 \%$ greater conversion than the control mitochondria. Therefore, it did not appear that sodium depletion merely altered the permeability of the mitochondria to allow more $\mathrm{NADPH}$ to enter.

The conversion of corticosterone to 18-hydroxycorticosterone was also studied. As shown in Fig. 3, the mitochondrial fraction of whole glands obtained from sodium-depleted rats demonstrated an increase in the ability to convert corticosterone to 18-hydroxycorticosterone, which paralleled the conversion of corticosterone to aldosterone. Although no correction was made for losses of 18hydroxycorticosterone in these samples, this increase was constant in all experiments.

The effect of different ionic media on the conversion of corticosterone to 18 -hydroxycorticosterone to aldosterone is also shown in Fig. 3. Krebs-Ringer bicarbonate, potassium phosphate, and Tris buffers were used. The different media
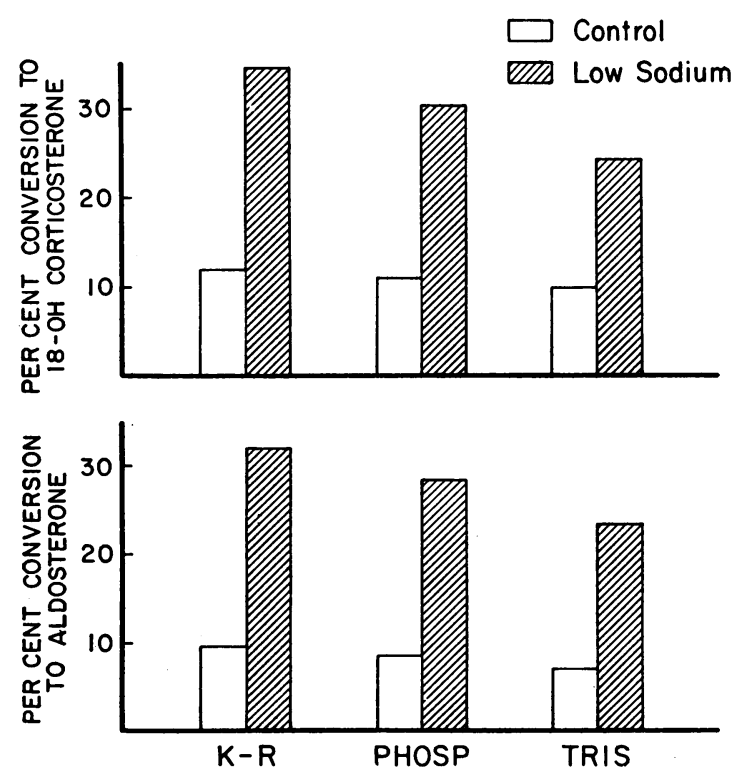

Fig. 3. EFFECT OF DIFFERENT BUfFERS ON THE CONVERSION OF CORTICOSTERONE-4 $-{ }^{14} \mathrm{C}$ TO ALDOSTERONE AND 18HYDROXYCORTICOSTERONE BY CONTROL AND LOW SODIUM RAT ADRENAL MITOCHONDRIA OBTAINED FROM THE W HOLE GLAND. $K-R$, Krebs-Ringer bicarbonate; Phosp, potassium phosphate buffer; Tris, $20 \mathrm{~mm}$ Tris buffer $\mathrm{pH}$ 7.4. The results are expressed as per cent corticosterone converted per milligram of mitochondrial protein nitrogen. The incubation was carried out for $1 \mathrm{hr}$.
TABLE I

Effect of different buffers

\begin{tabular}{rcccc}
\hline \hline & \multicolumn{4}{c}{ Corticosterone converted to aldosterone } \\
\cline { 2 - 5 } $\begin{array}{c}\text { Experi- } \\
\text { ment }\end{array}$ & $\begin{array}{c}\text { Sodium } \\
\text { phosphate }\end{array}$ & $\begin{array}{c}\text { Potassium } \\
\text { phosphate }\end{array}$ & $\begin{array}{c}\text { Tris } \\
\text { chloride }\end{array}$ & $\begin{array}{c}\text { Krebs- } \\
\text { Ringer }\end{array}$ \\
\hline 9 & $\%$ & $\%$ & $\%$ & $\%$ \\
21 & 7.7 & 5.2 & $\frac{\%}{7.2}$ & $\frac{-}{8.3}$ \\
24 & - & 7.0 & 5.7 & - \\
27 & - & 8.8 & 7.1 & 9.8 \\
\hline
\end{tabular}

Effect of different buffers on the conversion of corticosterone to aldosterone by whole adrenal mitochondria from rats fed a normal sodium diet. Results are expressed as per cent converted per milligram of mitochondrial nitrogen.

did not affect the enhanced conversion rate by mitochondria of sodium-depleted rats, although in the Tris buffer the absolute amount converted was smaller for both the control and sodium-depleted groups.

Furthermore, comparison of the effect of buffers of different ionic composition (sodium phosphate, potassium phosphate, Krebs-Ringer bicarbonate, Tris, and Tris plus addition of sodium and potassium chloride) on the conversion of corticosterone to aldosterone by the control rats mitochondria showed no striking difference despite marked variation in the sodium and potassium concentrations (Table I). In one experiment (not included in Table I) different amounts of sodium and (or) potassium were added to the Tris buffer, from 0 to 120 millimoles/liter. Varying the concentrations of the sodium and (or) potassium had no effect on the conversion of corticosterone to aldosterone.

The effect of substrate concentration on the increased conversion of corticosterone to aldosterone by the sodium-depleted rats was tested using 1,5 , $10,20,40$, and $100 \mu \mathrm{g}$ of corticosterone per flask. As is shown in Fig. 4, the enhanced conversion by the 4 day low sodium rat adrenal mitochondria was present throughout the substrate concentration range studied.

Further studies were designed to measure the specificity of the stimulus in the conversion of corticosterone to aldosterone by the low sodium rat mitochondria. Two other mitochondrial enzymes were simultaneously measured and compared in both groups. The enzymes selected were succinic dehydrogenase, a typical mitochondrial enzyme, and $11 \beta$-hydroxylase. $11 \beta$-Hydroxylase 


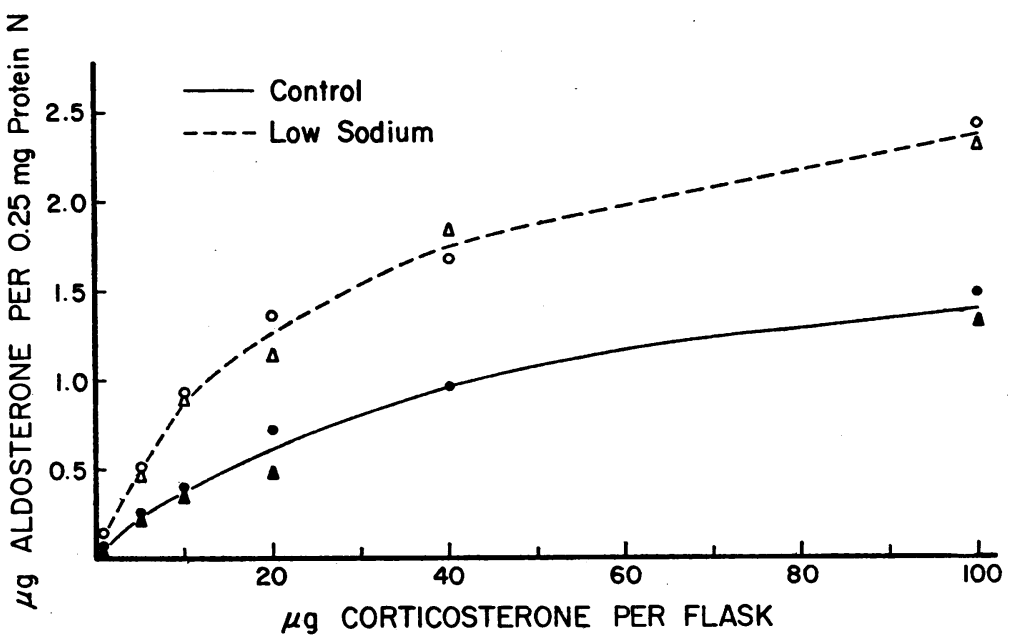

Fig. 4. EFfect of substrate concentration on the amount of alDOSTERONE PRODUCED BY MITOCHONDRIA FROM CONTROL (SOLID LINE) AND SODIUM-DEPLETED RATS (DASHED LINE). The results from each of four separate experiments are plotted individually; the open circles and triangles represent sodium-depleted rats and the closed circles and triangles represent normal rats. Between 0.25 and $0.28 \mathrm{mg}$ of mitochondrial protein nitrogen were added to each flask. The aldosterone results are corrected to $0.25 \mathrm{mg}$ of protein nitrogen.

is involved in the conversion of DOC to corticosterone, the step immediately preceding the last step in aldosterone biosynthesis. For this study it was necessary to separate the glomerulosa zone from inner zones since most of the mitochondria from the whole gland comes from fasciculatareticularis cells. The capsules of $20-30$ rats, containing mostly glomerulosa cells, were used in each experiment.

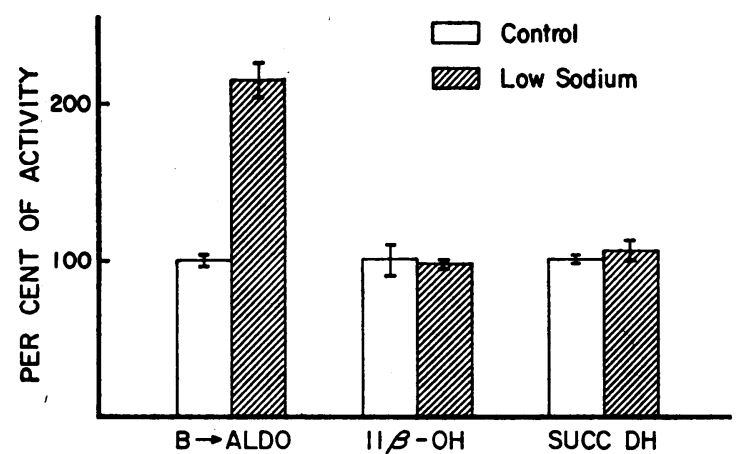

Fig. 5. COMParison of ADRENAL CAPSUlar MitochonDRIA ENZYMES FROM CONTROL AND SODIUM-DEPLETED RATS. The values of the control rats are expressed as $100 \%$ and those of the low sodium rats as per cent of the controls. Mean values and SEM are shown. $B \rightarrow$ Aldo, conversion of corticosterone to aldosterone; $11 \beta-\mathrm{OH}, 11 \beta$-hydroxylase activity; Succ $D H$, succinic dehydrogenase activity.
Results of the succinic dehydrogenase activity, $11 \beta$-hydroxylase, and conversion of corticosterone to aldosterone are shown in Fig. 5. The results per milligram of mitochondrial protein nitrogen from the 4-day depleted rats were compared with those from rats on a normal sodium intake. The values from the control rats were expressed as $100 \%$. The mean and standard error of the mean of three experiments are given. Succinic dehydrogenase and $11 \beta$-hydroxylase activities were of the same order of magnitude for both groups, but a marked increase of $239 \%$ in the conversion of corticosterone to aldosterone was present in the 4-day low sodium groups.

TABLE II

Conversion of DOC to corticosterone and aldosterone by adrenal capsular mitochondria

\begin{tabular}{|c|c|c|c|c|c|}
\hline \multirow{2}{*}{$\begin{array}{l}\text { Experi- } \\
\text { ment }\end{array}$} & \multirow[b]{2}{*}{ Diet } & \multicolumn{2}{|c|}{ Corticosterone } & \multicolumn{2}{|c|}{ Aldosterone } \\
\hline & & $\mu g^{*}$ & $\%$ change & $\overline{\mu \mathrm{g}^{*}}$ & $\%$ change \\
\hline 60 & $\begin{array}{l}\text { Normal } \\
\text { Low } \mathrm{Na}\end{array}$ & $\begin{array}{l}100 \\
113\end{array}$ & +13 & $\begin{array}{l}1.0 \\
3.4\end{array}$ & +340 \\
\hline 64 & $\begin{array}{l}\text { Normal } \\
\text { Low Na }\end{array}$ & $\begin{array}{l}77 \\
85\end{array}$ & +10 & $\begin{array}{l}1.0 \\
2.8\end{array}$ & +280 \\
\hline
\end{tabular}

15 min incubation.

* Micrograms produced per milligram of mitochondrial protein nitrogen. 
In two experiments DOC was used instead of corticosterone to determine its conversion to aldosterone since DOC is the precursor presented to the mitochondria; these experiments resemble more closely what occurs in vivo. The results are shown in Table III. DOC is rapidly converted to corticosterone by capsule mitochondria of the control and sodium-depleted rats. There was little difference between these groups. A marked increase in the conversion of DOC to aldosterone was present in the low sodium group. This is further evidence of an increase in the rate of the last biosynthetic steps, conversion of corticosterone to aldosterone, and makes it an unlikely possibility that the effect of sodium depletion is merely the result of increased permeability of the mitochondria to corticosterone.

\section{Discussion}

The major pathway for aldosterone biosynthesis appears to be cholesterol $\rightarrow$ pregnenolone $\rightarrow$ progesterone $\rightarrow$ DOC $\rightarrow \mathrm{B} \rightarrow 18$-hydroxycorticosterone $\rightarrow$ aldosterone. This synthesis takes place in the zona glomerulosa cells of the adrenal gland. The conversion of corticosterone to aldosterone occurs in the mitochondrial fraction of the cells.

There are four possible ways by which sodium depletion may stimulate aldosterone biosynthesis: (a) stimulate the early steps in the pathway, thus delivering more corticosterone to the mitochondrial site for conversion to aldosterone; $(b)$ stimulate the last steps, conversion of corticosterone to aldosterone; (c) produce hypertrophy or hyperplasia of the zona glomerulosa cells, and therefore increase the number of biosynthetic units (the increased aldosterone secretion would result from more units and not from an increased rate of any specific step); and (d) Stimulate by some combination of these three mechanisms.

One of the problems in studying the first steps, conversion of cholesterol to corticosterone, in the whole gland is that most of the corticosterone and its precursors are made in the fasciculata-reticularis zones. Therefore, any changes in the rate of conversion of cholesterol to corticosterone by the glomerulosa cells would be difficult to detect. Bledsoe, Island, and Liddle (4) attempted to minimize any contribution to corticosterone secretion from the fasciculata-reticularis zones by suppression of ACTH secretion with dexamethasone ther- apy. They found that sodium depletion in man stimulated corticosterone and aldosterone secretion several fold and interpreted these data to indicate that the early steps were increased. It is possible that the increased corticosterone secretion in man was a direct effect of angiotensin on the zona fasciculata cells. The argument against this possibility was that cortisol secretion was not increased, and hence there was no stimulation of the zona fasciculata. This argument presumes that the pathway from progesterone to corticosterone is under the same control as progesterone to cortisol. If corticosterone production in the zona fasciculata were preferentially stimulated by angiotensin, this reasoning would be invalid. The evidence concerning this point is contradictory. Incubation of angiotensin with beef adrenal slices consisting chiefly of fasciculata cells produced a threefold increase in corticosterone production and only a twofold increase in cortisol production (1). In the hypophysectomized dog, however, infusions of angiotensin stimulate corticosterone and cortisol secretion to the same extent (18). Another possible criticism is that their subjects were sodium depleted by administration of diuretics and a sodium-deficient diet for approximately 1-2 wk. Hypertrophy of the zona glomerulosa may have occurred and the increased number of biosynthetic units may have contributed to the increased corticosterone and aldosterone production.

Baniukiewicz et al. have shown in vivo that the conversion to aldosterone of tritiated corticosterone infused into sheep adrenal transplants was increased by mild sodium depletion, a finding that suggests an increase in the last steps. However, in severely sodium-depleted sheep, the conversion of corticosterone to aldosterone was decreased (3). As the authors pointed out, this inhibition of the conversion of corticosterone to aldosterone when high aldosterone secretion was present could be due to a simultaneous stimulation of another pathway, or inhibition of the transport of the radioactive corticosterone into the mitochondrial active site; but no evidence is available to support either possibility.

In addition these authors, studying hypophysectomized rats, found that sodium loading decreased the in vitro synthesis of corticosterone as well as the conversion of corticosterone to aldosterone. This effect on corticosterone synthesis was notice- 
able only during the first 30 min of incubation and not in the subsequent periods.

Another study of the biosynthetic steps stimulated by sodium depletion was carried out in hypophysectomized dogs. Sodium depletion increased corticosterone, cortisol, and aldosterone secretion (2). Since the increase in corticosterone secretion was greater than that of cortisol, the authors concluded that sodium depletion stimulated the early steps. The same argument presented in relationship to the human studies holds here as well. It is of interest that these results are at variance with the previous studies which showed corticosterone and coritsol to be stimulated to the same degree by angiotensin infusions. These authors (2) also showed that the conversion of corticosterone to aldosterone by dog adrenal gland slices was increased by sodium depletion, indicating stimulation of the last steps. However, since intraadrenal pool size of corticosterone was not measured, changes in pool size might account for the increase. In fact, the corticosterone production of the adrenal slices from sodium-depleted dogs was one-half that of slices from normal dogs.

Our studies were designed to avoid these limitations: by studying short-term sodium depletion in adult rats we minimized cell hypertrophy or hyperplasia, and by using an isolated mitochondrial fraction we minimized the influences of pool size of corticosterone and its precursors on the conversion of corticosterone to aldosterone. Also, the zona glomerulosa cells can be readily separated from the inner zones in the rat. The studies showed that the mitochondrial fraction from rats fed a low sodium diet for 1,2 , or 4 days has an increased rate of conversion of corticosterone to aldosterone. This increased rate of conversion is present throughout a wide range of substrate corticosterone concentration and appears to be independent of the sodium and potassium composition, NADPH, or a specific Krebs cycle intermediate in the incubation media. Cell hypertrophy or hyperplasia, which result in more mitochondria, seems an unlikely explanation since histological studies of these adrenals show little, if any, change in zona glomerulosa cell width. In the experiments with adrenal capsules, the failure to find an increase in the activity of two other mitochondrial enzymes, $11 \beta$-hydroxylase and succinic dehydrogenase, indicates that there was no increase in the number of mitochondria but rather a specific change in mitochondrial enzyme activity: conversion of corticosterone to aldosterone. This conclusion is limited by the fact that the glomerulosa zone of capsular tissue is contaminated by fasciculata cells. Histological studies of the capsular tissue suggest that there are from one-half to an equal number of fasciculata cells as there are glomerulosa cells. However, it would require twice as much contamination to mask any change in succinic dehydrogenase and $11 \beta$-hydroxylase activity completely.

Since there is no difference in the conversion of DOC to corticosterone by the mitochondria from normal or sodium-depleted rats, it appears unlikely that sodium depletion changes the permeability of the mitochondria to allow more steroid precursor to reach the enzymatic site for conversion to aldosterone. Similar results were obtained by McCarthy, Peron, and Guerra, in long-term sodiumdepleted rats (19). The fact that $11 \beta$-hydroxylase activity is unchanged suggests that there is no stimulation of the hydroxylation electron transfer chain or the respiratory electron transfer chain. Stimulation of hydroxylation by addition of maximal quantities of certain Krebs' cycle intermediates to the incubation media could not abolish the difference between the mitochondria from normal and sodium-depleted rats. It appears, therefore, that short-term sodium depletion stimulates the last steps in aldosterone biosynthesis through a specific enzymatic change in zona glomerulosa cell mitochondria. With prolonged sodium depletion an increased number of biosynthetic units develop by hypertrophy and hyperplasia of glomerulosa cells and this must also play a role. Stimulation of the early steps by delivering more corticosterone to the mitochondria can also lead to increased aldosterone secretion, as was shown in the substrate studies. These present studies have no bearing on whether early steps were stimulated, although preliminary experiments with capsular homogenates from 2-day sodium-depleted rats did not reveal increased corticosterone production (20).

It is of interest that neither the sodium nor the potassium concentration of the incubation media influenced the mitochondrial conversion of corticosterone to aldosterone, yet in vivo, the serum sodium and potassium concentrations can alter aldosterone secretion. These results may indicate 
that these ions influence aldosterone secretion by affecting an earlier step in the pathway.

The mechanism by which sodium depletion stimulates the enzymatic activity of the last steps is not clear. Presumably, sodium depletion stimulates release of a humoral factor which must alter the activity of a specific mitochondrial enzyme either through stimulating synthesis of a new enzyme or increasing enzyme activity. The reactions that take place in these series of events are completely unknown. In the rat, there is conflicting evidence as to whether angiotensin is the humoral factor, since infusions of angiotensin have little effect on aldosterone secretion (21). Moreover, Müller (5) could not show a stimulation with angiotensin of the conversion of corticosterone to aldosterone by rat adrenal quarters in vitro. With beef adrenal slices, Kaplan and Bartter (1) were able to show a stimulation by angiotensin of the conversion of cholesterol to aldosterone but not corticosterone to aldosterone. Since sodium depletion stimulates the last steps, these studies suggest that a mechanism other than angiotensin is responsible for the increased conversion of corticosterone to aldosterone in the rat.

\section{Acknowledgment}

We are grateful for the technical assistance of $\mathrm{Mr}$. Dennis Martell and Mr. Walter Hirniak.

\section{References}

1. Kaplan, N. M., and F. C. Bartter. 1962. The effect of ACTH, renin, angiotensin II, and various precursors on biosynthesis of aldosterone by adrenal slices. J. Clin. Invest. 41 : 715.

2. Davis, W. W., L. R. Burwell, G. Kelley, A. G. T. Casper, and F. C. Bartter. 1966. Studies of the loci of stimulation of aldosterone biosynthesis during sodium depletion. Biochem. Biophys. Res. Commun. 22 : 218.

3. Baniukiewicz, S., A. Brodie, C. Flood, M. Motta, M. Okamoto, J. F. Tait, S. A. S. Tait, J. R. BlairWest, J. P. Coghlan, D. A. Denton, J. R. Goding, B. A. Scoggins, E. M. Wintour, and R. D. Wright. Adrenal biosynthesis of steroids in vitro and in vivo using continuous superfusion and infusion procedures. In Functions of the Adrenal Cortex. K. W. McKerns, editor. In press.

4. Bledsoe, T., D. P. Island, and G. W. Liddle. Studies of the mechanism through which sodium depletion increases aldosterone biosynthesis in man. 1966. J. Clin. Invest. 45 : 524.

5. Müller, J. 1966. Aldosterone stimulation in vitro: III. Site of action of different aldosterone-stimu- lating substances on steroid biosynthesis. Acta Endocrol. 52 : 515.

6. Stachenko, J., and C. J. P. Giroud. 1964. Further observations on the functional zonation adrenal cortex. Can. J. Biochem. Physiol. 42: 1777.

7. Marusic, E. T., and P. J. Mulrow. 1967. In vitro conversion of corticosterone-4- ${ }^{14} \mathrm{C}$ to 18 -hydroxycorticosterone by zona fasciculata-reticularis of beef adrenal. Endocrinology. $80: 214$.

8. Psychoyos, S., H. H. Tallan, and P. Greengard. 1966. Aldosterone synthesis by adrenal mitochondria. J. Biol. Chem. $241: 2949$.

9. Raman, P. B., D. C. Sharma, and R. I. Dorfman. 1966. Aldosterone biosynthesis in vitro. Biochemistry. 5 : 1795.

10. Giroud, C. J. P., J. Stachenko, and E. H. Venning. 1956. Secretion of aldosterone by the zona glomerulosa of rat adrenal glands incubated in vitro. Proc. Soc. Exptl. Biol. Med. 92 : 154.

11. Manitius, A., H. Levitin, D. Beck, and F. H. Epstein. 1960. On the mechanism of impairment of renal concentrating ability in potassium deficiency. $J$. Clin. Invest. 39 : 684.

12. Schneider, W. C. 1957. Methods for the isolation of particulate components of the cell. In Manometric Techniques. W. N. Umbreit, R. H. Burris, and J. F. Stauffer, editors. Burgess Publishing Co., Minneapolis. 3rd edition. 188.

13. Lowry, O. H., N. J. Rosebrough, A. L. Farr, and R. J. Randall. 1957. Protein measurement with the folin phenol reagent. J. Biol. Chem. $193: 265$.

14. Slater, E. C., and W. D. Bonner. 1952. The effect of fluoride on the succinic oxidase system. Biochem. J. 52 : 185.

15. Neher, R. 1964. Steroid chromotography. Elsevier Publishing Co., Amsterdam. 2nd edition. 181.

16. Kliman, B., and R. E. Peterson. 1960. Double isotope derivative assay of aldosterone in biological extracts. J. Biol. Chem. 235: 1639.

17. Silber, R. H., R. D. Busch, and R. Oslapas. 1958. Practical procedure for estimation of corticosterone and hydrocorticosterone. Clin. Chem. $4: 278$.

18. Slater, J. D. H., B. H. Barbour, H. H. Henderson, A. G. T. Casper, and F. C. Bartter. 1963. Influence of the pituitary and the renin-angiotensin system on the secretion of aldosterone, cortisol, and corticosterone. J. Clin. Invest. 42: 1504.

19. McCarthy, J., F. G. Peron, and F. C. Guerra. 1965. Adrenal corticosteroidogenesis by mitochondria from rats given normal and sodium deplete diets Excerpta Med. Internat. Congr. Ser. 99. E 82.

20. Marusic, E. T., and P. J. Mulrow. 1967. Stimulation of aldosterone biosynthesis in adrenal mitochondria by sodium depletion. J. Clin. Invest. 46: 1092.

21. Marieb, N. J., and P. J. Mulrow. 1965. Role of the renin-angiotensin system in the regulation of aldosterone secretion in the rat. Endocrinology. 76: 657. 